BMJ Open

Diabetes

Research

\& Care

\title{
Democratizing type 1 diabetes specialty care in the primary care setting to reduce health disparities: project extension for community healthcare outcomes (ECHO) T1D
}

Ashby F Walker (DD , ${ }^{1,2}$ Nicolas Cuttriss, ${ }^{3}$ Michael J Haller (D) ,1,4 Korey K Hood, ${ }^{3,5}$ Matthew J Gurka, ${ }^{6}$ Stephanie L Filipp, ${ }^{6}$ Claudia Anez-Zabala, ${ }^{4}$ Katarina Yabut, ${ }^{3}$ Xanadu Roque, ${ }^{4}$ Jessie J Wong, ${ }^{3}$ Linda Baer, ${ }^{3}$ Lauren Figg, ${ }^{3}$ Angelina Bernier, ${ }^{4}$ Sarah Westen, ${ }^{7}$ Eugene Lewit, ${ }^{8}$ Eleni Sheehan, ${ }^{4}$ Marina Basina, ${ }^{3,9}$ Rayhan Lal, ${ }^{3,9}$ Jennifer Maizel, ${ }^{10}$ David M Maahs ${ }^{3}$

\section{ABSTRACT}

Introduction Project ECHO (Extension for Community Healthcare Outcomes) is a tele-education outreach model that seeks to democratize specialty knowledge to reduce disparities and improve health outcomes. Limited utilization of endocrinologists forces many primary care providers (PCPs) to care for patients with type 1 diabetes (T1D) without specialty support. Accordingly, an ECHO T1D program was developed and piloted in Florida and California. Our goal was to demonstrate the feasibility of an ECHO program focused on T1D and improve PCPs' abilities to manage patients with T1D.

- Supplemental material is published online only. To view, please visit the journal online (http://dx.doi.org/10.1136/ bmjdrc-2021-002262).

Received 11 March 2021 Accepted 5 June 2021

Check for updates

\section{(c) Author(s) (or their} employer(s)) 2021. Re-use permitted under CC BY-NC. No commercial re-use. See rights and permissions. Published by BMJ.

For numbered affiliations see end of article.

Correspondence to Dr Ashby F Walker; afwalker@ufl.edu
Research design and methods Health centers (ie, spokes) were recruited into the ECHO T1D pilot through an innovative approach, focusing on Federally Qualified Health Centers and through identification of high-need catchment areas using the Neighborhood Deprivation Index and provider geocoding. Participating spokes received weekly tele-education provided by the University of Florida and Stanford University hub specialty team through virtual ECHO clinics, real-time support with complex T1D medical decision-making, access to a diabetes support coach, and access to an online repository of diabetes care resources. Participating PCPs completed pre/ post-tests assessing diabetes knowledge and confidence and an exit survey gleaning feedback about overall ECHO T1D program experiences.

Results In Florida, 12 spoke sites enrolled with 67 clinics serving >1000 patients with T1D. In California, 11 spoke sites enrolled with 37 clinics serving $>900$ patients with T1D. During the 6-month intervention, 27 tele-education clinics were offered and $n=70$ PCPs (22 from Florida, 48 from California) from participating spoke sites completed pre/ post-test surveys assessing diabetes care knowledge and confidence in diabetes care. There was statistically significant improvement in diabetes knowledge $(\mathrm{p} \leq 0.01)$ as well as in diabetes confidence $(p \leq 0.01)$.

Conclusions The ECHO T1D pilot demonstrated proof of concept for a T1D-specific ECHO program and represents a viable model to reach medically underserved communities which do not use specialists.

\section{Significance of this study}

What is already known about this subject?

- As a result of multifaceted barriers surrounding utilization of endocrinologists, many patients with type 1 diabetes (T1D) see primary care providers (PCPs) for support in managing their diabetes instead of specialists.

What are the new findings?

- PCPs demonstrated a statistically significant increase in diabetes knowledge and confidence by participating in the Project ECHO (Extension for Community Healthcare Outcomes) T1D pilot.

- This pilot demonstrates the feasibility of a T1Dspecific ECHO program and the successful recruitment of PCPs from Federally Qualified Health Centers.

How might these results change the focus of research or clinical practice?

- The ECHO T1D program can address the needs of underserved T1D communities that do not regularly use specialty care.

\section{INTRODUCTION}

In the USA, approximately 1.6 million people have type 1 diabetes (T1D). ${ }^{1}$ The American Diabetes Association (ADA) recommends multidisciplinary care for people with T1D, but not all people with T1D are able to regularly use care at diabetes specialty centers due to a variety of factors including distance from a center, lack of sufficient diabetes specialists, and financial issues. ${ }^{2-5}$ Furthermore, data from the T1D Exchange indicate that only $17 \%$ of youth and $21 \%$ of adults with T1D seen at diabetes specialty centers meet the 
ADA hemoglobin Alc (HbAlc) goals. ${ }^{2}$ A report based on insurance claims data suggests that HbAlc values may be higher in adults with T1D who do not receive care at diabetes specialty centers. ${ }^{6}$ In particular, disparate health outcomes are pronounced for T1D communities from low socioeconomic status households and for racial and ethnic minority groups. ${ }^{7-14}$ These differences have been magnified in the COVID-19 pandemic. ${ }^{15-20}$ Recent research with underserved communities with T1D demonstrates that negative encounters with endocrinologists and associated feelings of stigma are an additional barrier to receiving preventative endocrinology care. ${ }^{21}$ Given the multifaceted barriers responsible for underutilization of endocrinology care, novel programs to improve health outcomes are needed to reach people with T1D, especially those from medically underserved communities. $^{22}$

One such tele-education model is the Extension for Community Healthcare Outcomes (ECHO), which was developed to improve access to care for underserved populations with complex health problems. ${ }^{23}{ }^{24}$ ECHO is a 'hub-and-spoke' model of education and guided practice, which leverages videoconferencing technology to connect specialists with learners across geographic distances. ${ }^{23}{ }^{24}$ To address the identified need to improve care for people with T1D who are not seen at diabetes specialty centers, we developed the 'Project ECHO T1D' tele-education clinic adapted from the Project ECHO model $^{2526}$ in collaboration with community primary care providers (PCPs) who care for people with T1D at nonspecialty diabetes practices across the states of Florida (FL) and California (CA).

Our specific aims in this pilot and feasibility study were to: (1) demonstrate proof of concept for adaptation of the Project ECHO model to include adult and pediatric patients with T1D in CA and FL; and (2) increase the capacity of PCPs to empower and safely and effectively manage underserved patients with T1D who do not receive routine specialty care.

\section{METHODS}

A preliminary needs assessment was conducted in FL and $\mathrm{CA}$ prior to program implementation including surveys with PCPs and focus groups with medically underserved adults with T1D. Surveys with PCPs were designed to better understand barriers for T1D care delivery in primary care settings. Publicly available statewide provider directories in FL and CA were used for PCP survey recruitment. Participants received a $\$ 25$ gift card link for survey completion. Focus groups were also conducted with adults 18 years and older with T1D who met selection criteria including: (1) hospitalized in the past year for diabetic ketoacidosis or (2) received routine care at a Federally Qualified Health Center (FQHC) ${ }^{27}$ or (3) have HbAlc $>9 \%$ and 'no showed' to two consecutive endocrinology visits. Focus groups lasted 1 hour and used a standard script to glean information about barriers related to T1D care. Participants were compensated $\$ 65$ for their time.

Data from the initial needs assessment with $n=123$ PCPs in FL and CA indicate that there are critical knowledge gaps in areas such as diabetes technology; for example, continuous glucose monitoring (CGM) or CGM and insulin pumps. ${ }^{28}$ Data from 16 focus groups conducted in English and Spanish with $\mathrm{n}=86$ medically underserved adults with T1D reiterated the need for provider education focused on diabetes technology, as focus group participants listed provider-level factors related to obtaining diabetes technology as one of the greatest barriers to achieving optimal health in T1D. ${ }^{21}$ Findings from these preliminary efforts aided in curriculum development for the weekly tele-education ECHO clinics as well as the development of priority areas for the Diabetes Support Coaches to focus on for patient engagement.

On completion of the needs assessment, health centers (ie, 'spokes') providing care for medically underserved communities were strategically recruited for Project ECHO T1D by: (1) focusing on FQHCs and (2) the use of the Neighborhood Deprivation Index (NDI) and provider geocoding. ${ }^{26}$ Covered under the Consolidated Health Center Program of the Social Security Act, FQHCs in the USA provide primary care services to underserved areas and must adhere to stringent guidelines including never turning patients away based on insurance status, and, providing care on a sliding scale based on ability to pay. ${ }^{27}$ To identify high-need geographic catchment areas in FL and CA, the NDI was used in conjunction with geocoding of PCPs and endocrinologists in each state to concurrently identify areas with low endocrinology provider density and high health risk/poverty areas. Spokes recruited for participation received a onetime stipend of \$1200-\$2500 to participate in the Project ECHO T1D pilot for 6 months and to identify a 'champion', that is, the lead PCP to represent their health center in the program.

\section{The Project ECHO T1D intervention}

Participating spokes received weekly tele-education through the use of Zoom (Zoom Video Communications, San Jose, California, USA), real-time access to support from the multidisciplinary 'hub' team (endocrinologists, behavioral health specialists, dietitians, etc) with complex medical decision-making, access to a Diabetes Support Coach, and access to an online repository of recorded tele-education ECHO clinics and other diabetes resources for PCPs. Figure 1 shows the Project ECHO T1D hub-and-spoke model, and online supplemental appendix A includes a listing of all participating members. Prior to the launch of Project ECHO T1D, spokes attended a 'kickoff' orientation event in each respective state designed to foster rapport building with the hub team and community partners and to outline expectations for program participation. In keeping with the Project ECHO model established by the University of New Mexico (UNM), ${ }^{23}{ }^{24}$ weekly tele-education sessions 


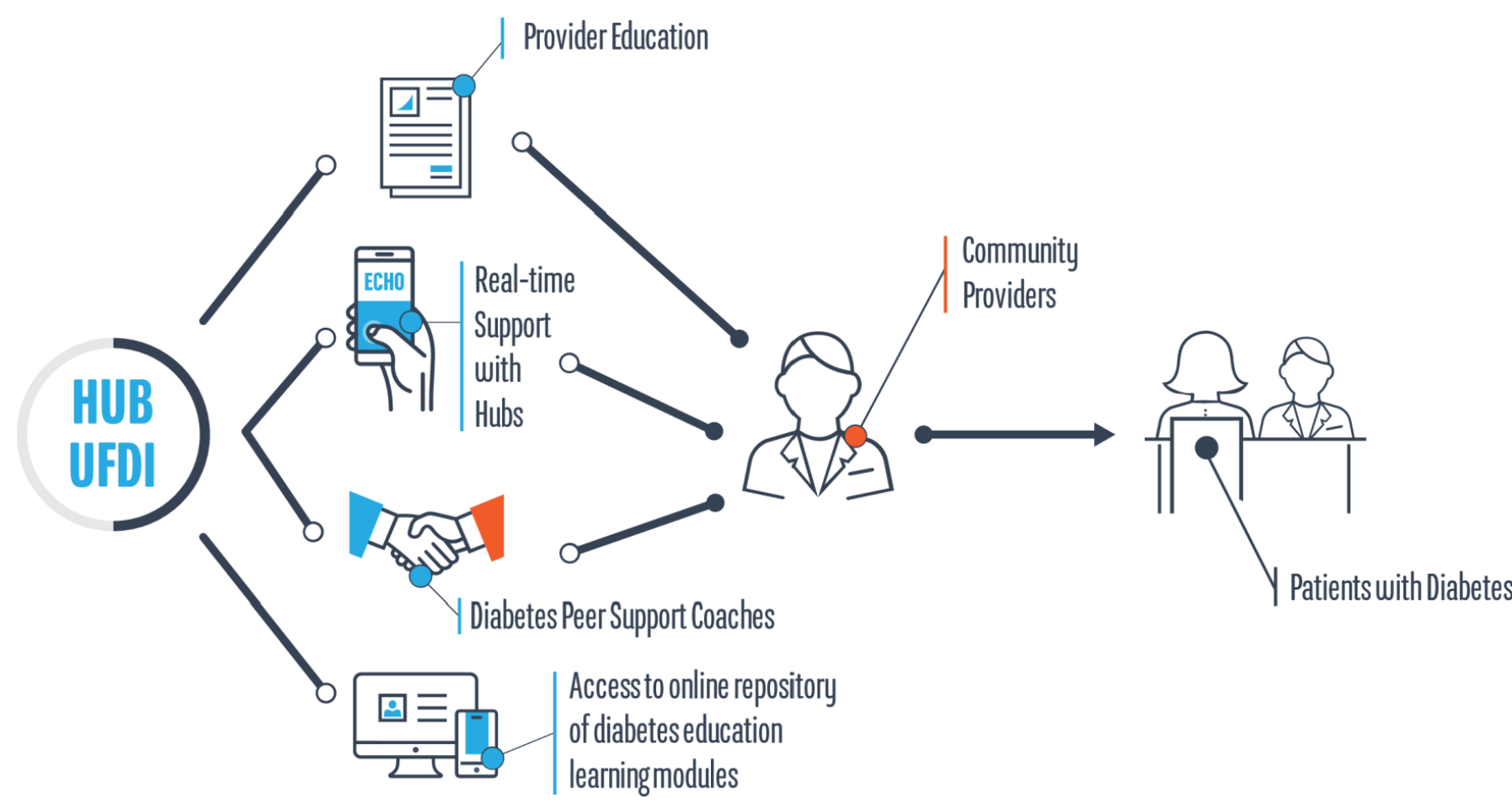

Figure 1 Project ECHO T1D model. ECHO, Extension for Community Healthcare Outcomes; T1D, type 1 diabetes; UFDI, University of Florida Diabetes Institute.

included a 20-30 min learning didactic on diabetes care followed by one or two de-identified case presentations by the spokes. Participating providers received continuing medical education (CME) credits for attending teleECHO sessions and completed weekly CME evaluations. Additionally, they completed pre/post-test surveys administered via REDCap (Research Electronic Data Capture) prior to and after the 6-month intervention assessing knowledge (using 11 multiple-choice test questions) and confidence (using 27 questions with a 4-point Likert scale response set ranging from 'not at all confident' to 'extremely confident') in diabetes care.

Outside of tele-ECHO clinics, participating spokes had access to the hub team when faced with complex realtime T1D care questions. Spokes were provided with direct contact numbers (ie, cell phone access) for each hub team member and provided with a call list denoting whom to contact for different types of diabetes-related questions. Each 'real-time' support contact by a spoke was tracked to document the types of issues the spokes faced, the hub team member that responded, and how the issue was resolved. Spokes were also given access to a Diabetes Support Coach for engagement of patients with T1D. Diabetes Support Coaches hold invaluable expert knowledge as they live with diabetes themselves or have a family member with diabetes, and are local to the geographic catchment areas they serve. This unique role combines a traditional community health worker (CHW) role with peer support models. Diabetes Support Coaches complete standardized training in health coaching from the University of California San Francisco's Center for Excellence in Primary Care, receive
Diabetes Paraprofessional Level 1 certification through the Association of Diabetes Care and Education Specialists, and have access to the ADA's CHW membership and toolkits. Diabetes Support Coaches offer one-on-one peer support for interested patients, create local resource guides for diabetes management, host community events, disseminate information about technologies like CGM, and assist with appointment reminders and other engagement activities. Patient encounters with Diabetes Support Coaches were documented in REDCap.

Surveys and data collection were facilitated through the REDCap research tool. All data management and analytics were conducted using SAS V.9.4. Descriptive statistics were computed for key outcomes and statistical significance evaluated with a predetermined threshold of $\alpha=0.05$. Categorical data are presented $n(\%)$, and continuous data were summarized median (IQR), due to skewedness. Wilcoxon signed-rank test was used to evaluate differences in knowledge and confidence scores among PCPs from pre-test to post-test.

\section{RESULTS}

In FL, 12 spoke sites enrolled with 67 clinics serving $>1000$ patients with T1D. In CA, 11 spoke sites enrolled with 37 clinics serving $>900$ patients with T1D. During the 6-month intervention, 27 tele-education clinics were offered and of 92 queried, 70 PCPs (22 from FL, 48 from CA) from participating spoke sites responded to both pre-test and post-test surveys assessing diabetes care knowledge and confidence in diabetes care. There was a statistically significant improvement in diabetes 


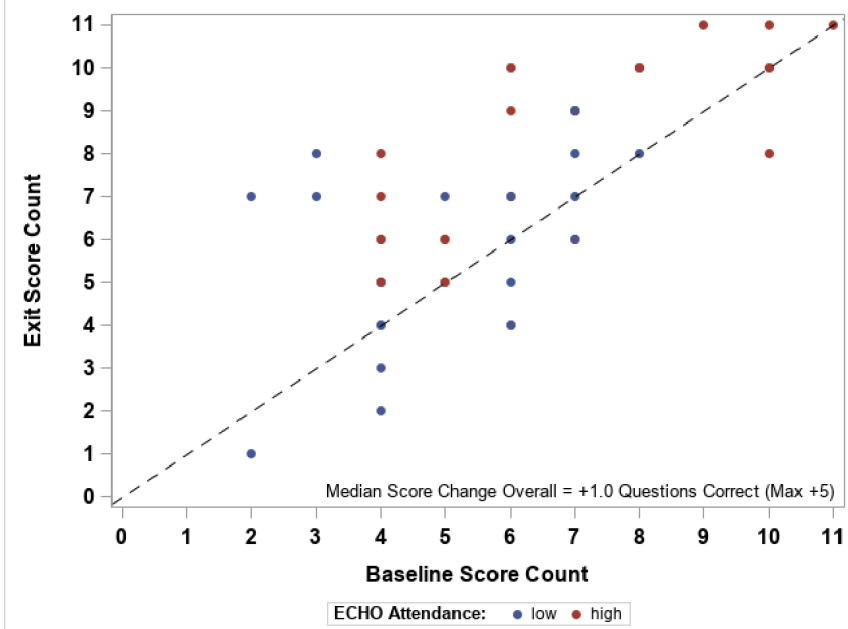

Figure 2 Diabetes knowledge acquisition change. Median: 1.0 IQR: (0.0-2.0), p value: 0.0003. ECHO, Extension for Community Healthcare Outcomes.

knowledge (median: 1.0 IQR: $(0.0-2.0), \mathrm{p}=<0.01)$ among the 56 providers completing the full question set (ie, without skipping any questions). Additionally, change in diabetes confidence evaluated on a 4-point Likert scale was positive and statistically significant among the 41 completing all questions for both pre-test and post-test (median: 0.6, IQR: $(0.3-0.9), \mathrm{p}=<0.01$ ) (figures 2 and 3). Exit surveys were also completed by PCPs with $95 \%$ of ( $n=65$ responding) participants reporting they would recommend Project ECHO T1D to a colleague and 63\% $(\mathrm{n}=68$ responding) reporting that what they learned in tele-ECHO clinics resulted in changes in their T1D medical practices (with diabetes technology changes most commonly cited). Overall, exit surveys with PCPs indicated high levels of satisfaction with Project ECHO T1D (table 1).

In FL, five Diabetes Support Coaches were hired to work with participating spokes and six were hired in CA.

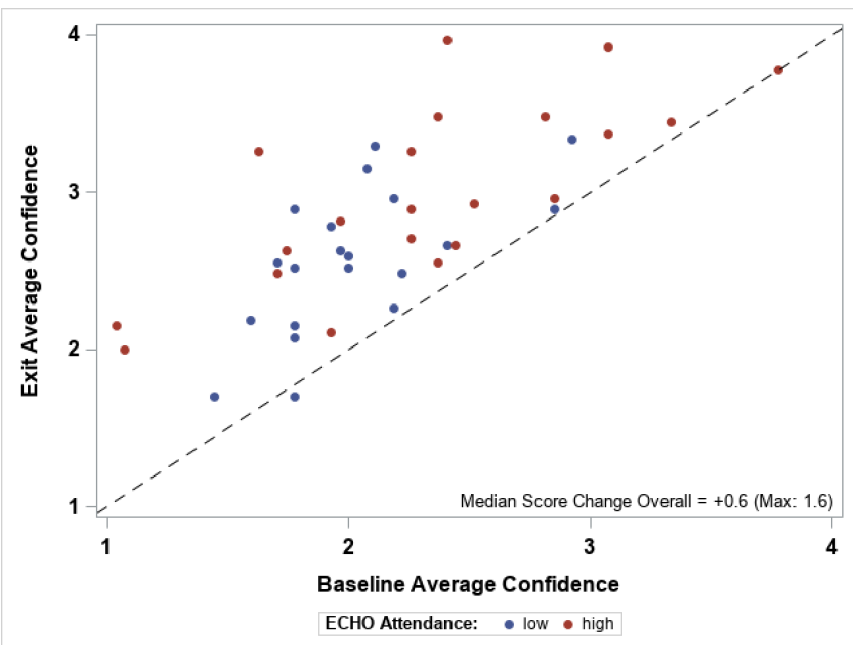

Figure 3 Diabetes confidence change. Median: 0.6 IQR: (0.3-0.9), p value: $<0.0001$. ECHO, Extension for Community Healthcare Outcomes.
Collectively, the Diabetes Support Coaches spearheaded 23 social events for communities with T1D at participating spoke locations (mean attendance in FL 38 per event, and 5 in CA). Diabetes Support Coaches created local T1D resource guides in Spanish and English for all spokes including critical information on insulin assistance programs, food insecurity resources, and local/ national T1D support programs for behavioral health and social network support. The Diabetes Support Coaches worked one-on-one with a total of 124 patients with T1D (82 in FL, 42 in CA) that signed 'peer support contracts'. Patients opted to receive intensive, weekly outreach from their coach via text, phone calls and in-person visits. Over this period, Diabetes Support Coaches facilitated 795 outreach interactions with enrolled patients in FL, and 605 in CA. Table 2 shows the types of concerns expressed by patients with T1D working with Diabetes Support Coaches during the 6-month pilot.

\section{CONCLUSIONS}

The Project ECHO T1D pilot successfully established feasibility of a T1D-specific ECHO and demonstrated significant improvement in diabetes knowledge and confidence for participating PCPs. To our knowledge, we were the first Project ECHO program to strategically recruit using a dual focus on FQHCs and using the NDI with provider geocoding. ${ }^{26}$ By including targeted recruitment methods to identify spokes delivering care to medically underserved communities, the Project ECHO T1D pilot program reached PCPs in critical need of resources to help offset pronounced health disparities in the communities they serve. Feedback from the PCPs also indicates the participants found the program a worthy investment of their time both in terms of the quality of content presented in tele-ECHO clinics and through the provision of a Diabetes Support Coach for patient engagement.

Given that ECHO T1D was a pilot and feasibility project, one of the major limitations is an inadequate ability to document the impact of this intervention on patient-level outcomes. While we focused on providerlevel outcomes like acquisition of diabetes knowledge and confidence, a foundational assumption guiding the Project ECHO model is that there is a benefit to medically underserved patients. The current, expanded implementation of our ECHO program now includes a rigorous evaluation of patient-level outcomes that requires longer duration of time and systematic approach (ie, steppedwedge trial design) ${ }^{29}$ that was not possible with our pilot. It is important to note that as the Project ECHO model is increasingly used nationally and internationally with implementation particulars varying widely across settings, discussions about evaluating the impact of these programs are paramount.

With the devastating impact of COVID-19 for minority and underserved communities revealing longstanding and systemic inequality in the USA ${ }^{15-20}$ there has never 


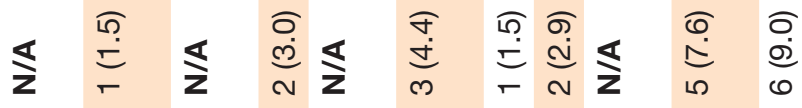

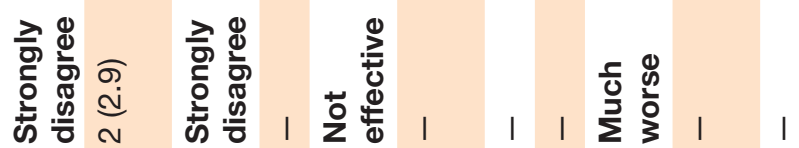

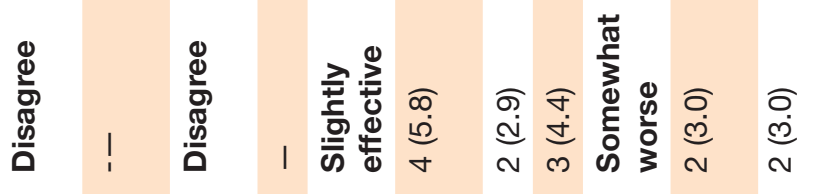

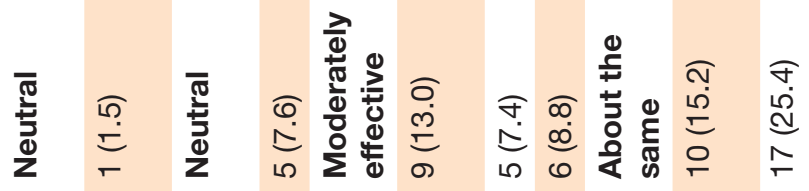

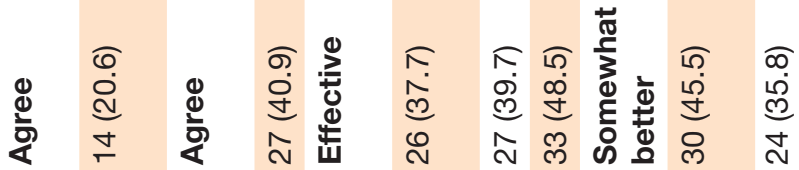

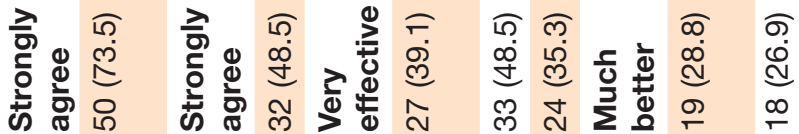

ำ

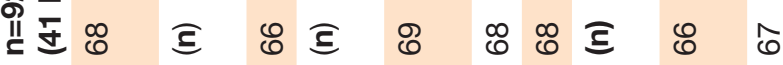

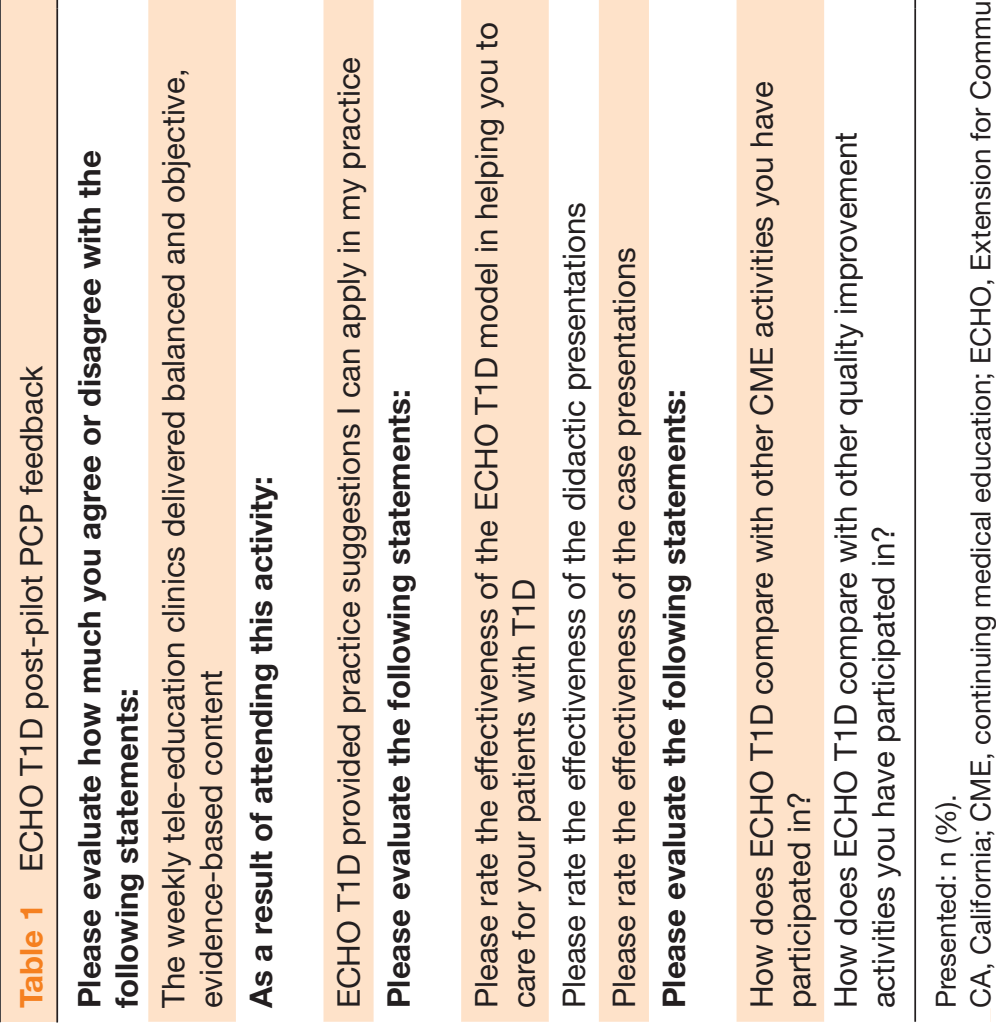


Table 2 T1D patient concerns expressed to Diabetes Support Coach

\begin{tabular}{|c|c|}
\hline \multicolumn{2}{|l|}{ Florida } \\
\hline $\begin{array}{l}\text { Patient expressed concerns or had } \\
\text { questions regarding:* }\end{array}$ & $\begin{array}{l}n=795 \text { patient } \\
\text { encounters }\end{array}$ \\
\hline Medications & $464(58.4)$ \\
\hline Food & $252(31.7)$ \\
\hline Exercise & $195(24.5)$ \\
\hline Stress & $251(31.6)$ \\
\hline $\mathrm{HbA1c}$ & $176(22.1)$ \\
\hline Blood pressure & $17(2.1)$ \\
\hline Cholesterol & $4(0.5)$ \\
\hline Weight & $29(3.7)$ \\
\hline Working with the provider & $165(20.8)$ \\
\hline Using the clinic/resources & $207(26.0)$ \\
\hline Other & $64(8.1)$ \\
\hline \multicolumn{2}{|l|}{ California } \\
\hline $\begin{array}{l}\text { Patient expressed concerns or had } \\
\text { questions regarding: }\end{array}$ & $\begin{array}{l}n=605 \text { patient } \\
\text { encounters }\end{array}$ \\
\hline Medications & $197(32.6)$ \\
\hline Food & $197(32.6)$ \\
\hline Exercise & $152(25.1)$ \\
\hline Stress & $189(31.2)$ \\
\hline $\mathrm{HbA1c}$ & $77(12.7)$ \\
\hline Blood pressure & $20(3.3)$ \\
\hline Cholesterol & $12(2.0)$ \\
\hline Weight & $37(6.1)$ \\
\hline Working with the provider & $173(28.6)$ \\
\hline Using the clinic/resources & $136(22.5)$ \\
\hline Other & $112(18.5)$ \\
\hline
\end{tabular}

*Multiple areas of concern could be selected per encounter. $\mathrm{HbA1c}$, hemoglobin A1c; T1D, type 1 diabetes.

been a more critical time for innovative T1D programs that not only increase access to care but also improve patient outcomes. Racial, socioeconomic, and geographic disparities persist, and are in some cases widening, in patients' utilization of diabetes technology, access to endocrinologists and healthcare, overall glycemic control, and risk of mortality. ${ }^{7-14}$ Results of this pilot study demonstrate that the ECHO T1D program addresses these gaps by equipping more PCPs with the knowledge and resources to support patients with T1D who may not otherwise receive adequate or routine specialty care. Additionally, as the pilot program specifically targets FQHCs in underserved communities, it offers a solution to disparities shaped by patients' geographic location, race/ethnicity, and socioeconomic status. Furthermore, the usage of Diabetes Support Coaches in ECHO T1D may combat these disparities and offers patients more psychosocial support. Further evaluation of these positions is needed.
Despite the challenges related to evaluation of Project ECHO programs, our pilot demonstrated proof of concept for a T1D-specific implementation and used creative and pioneering efforts at precision spoke recruitment. The success of our pilot's recruitment efforts represses skepticism that PCPs may not have enough time to participate or interest in T1D because of their already complex patient panels. On the contrary, most participating PCPs indicated that they would recommend the program to a colleague, which demonstrates that they found it to be valuable. By recruiting Diabetes Support Coaches who lived with T1D themselves, we also expanded the traditional role of the CHW promoted by UNM's Project ECHO model to include a peer support model. These new approaches to T1D care would likely translate to the care of patients with type 2 diabetes (T2D) who use multiple daily injections and other patients with diabetes. This presents a potentially monumental opportunity to expand the Project ECHO model to undeserved communities with T2D, which experience many of the same as well as unique disparities in healthcare and outcomes. As COVID-19 continues to reveal longstanding and pervasive inequalities among all people with diabetes in the USA, adaptation of programs like Project ECHO for this patient population will be increasingly vital as PCPs play a critical role in addressing the needs of medically underserved communities which do not use specialists.

\section{Author affiliations}

${ }^{1}$ University of Florida Diabetes Institute, Gainesville, FL, USA

${ }^{2}$ Department of Health Services Research, Management and Policy, University of Florida, Gainesville, FL, USA

${ }^{3}$ Department of Pediatrics and Division of Pediatric Endocrinology and Diabetes, Stanford University, Palo Alto, California, USA

${ }^{4}$ Department of Pediatrics, University of Florida, Gainesville, Florida, USA

${ }^{5}$ Department of Psychiatry and Behavioral Sciences, Stanford University, Stanford, CA, USA

${ }^{6}$ Department of Health Outcomes and Biomedical Informatics, University of Florida, Gainesville, Florida, USA

${ }^{7}$ Department of Clinical and Health Psychology, University of Florida, Gainesville, Florida, USA

${ }^{8}$ Department of Health Research and Policy, Stanford, Palo Alto, California, USA ${ }^{9}$ Department of Medicine, Division of Endocrinology, Gerontology \& Metabolism, Stanford University, Palo Alto, California, USA

${ }^{10}$ College of Public Health and Health Professions, University of Florida, Gainesville, Florida, USA

Contributors AFW helped design the study, oversaw study operations and wrote the manuscript. DMM, MJH, and NC helped design the study and oversaw all study operations. MJG and SLF aided in study design, had access to data, and conducted data analysis. KKH, SW, LB, JJW, EL, CA-Z, XR, ES, MB, RL, JM, AB, and LF contributed input to the study design, reviewed findings, and provided critical revisions to the manuscript. All authors have reviewed and approved this version of the manuscript. AFW and DMM are the guarantors of this work and, as such, had full access to all the data and take full responsibility for the integrity of the data and the accuracy of the analysis.

Funding Funding for this study was provided by the Leona M and Harry $B$ Helmsley Charitable Trust (2019 PG-T1D052).

Competing interests None declared.

Patient consent for publication Not required.

Ethics approval This study was approved by the institutional review boards at UF and Stanford. 
Provenance and peer review Not commissioned; externally peer reviewed.

Data availability statement Data are available upon reasonable request.

Supplemental material This content has been supplied by the author(s). It has not been vetted by BMJ Publishing Group Limited (BMJ) and may not have been peer-reviewed. Any opinions or recommendations discussed are solely those of the author(s) and are not endorsed by BMJ. BMJ disclaims all liability and responsibility arising from any reliance placed on the content. Where the content includes any translated material, BMJ does not warrant the accuracy and reliability of the translations (including but not limited to local regulations, clinical guidelines, terminology, drug names and drug dosages), and is not responsible for any error and/or omissions arising from translation and adaptation or otherwise.

Open access This is an open access article distributed in accordance with the Creative Commons Attribution Non Commercial (CC BY-NC 4.0) license, which permits others to distribute, remix, adapt, build upon this work non-commercially, and license their derivative works on different terms, provided the original work is properly cited, appropriate credit is given, any changes made indicated, and the use is non-commercial. See: http://creativecommons.org/licenses/by-nc/4.0/.

ORCID IDS

Ashby F Walker http://orcid.org/0000-0002-7554-2344

Michael J Haller http://orcid.org/0000-0002-2803-1824

\section{REFERENCES}

1 Centers for Disease Control and Prevention. National diabetes statistics report, 2020, 2020. Available: https://www.cdc.gov/ diabetes/data/statistics-report/index.html

2 Foster NC, Beck RW, Miller KM, et al. State of type 1 diabetes management and outcomes from the T1D exchange in 2016-2018. Diabetes Technol Ther 2019;21:66-72.

3 American Diabetes Association. 4. Comprehensive medical evaluation and assessment of comorbidities: Standards of Medical Care in Diabetes-2021. Diabetes Care 2021;44:S40-52.

$4 \mathrm{Lu} \mathrm{H}$, Holt JB, Cheng YJ, et al. Population-Based geographic access to endocrinologists in the United States, 2012. BMC Health Serv Res 2015;15:541

5 Hill-Briggs F, Adler NE, Berkowitz SA, et al. Social determinants of health and diabetes: a scientific review. Diabetes Care 2021;44:258-79.

6 Pettus JH, Zhou FL, Shepherd L, et al. Incidences of severe hypoglycemia and diabetic ketoacidosis and prevalence of microvascular complications stratified by age and glycemic control in U.S. adult patients with type 1 diabetes: a real-world study. Diabetes Care 2019;42:2220-7.

7 Secrest AM, Costacou T, Gutelius B, et al. Association of socioeconomic status with mortality in type 1 diabetes: the Pittsburgh epidemiology of diabetes complications study. Ann Epidemiol 2011;21:367-73.

8 Secrest AM, Costacou T, Gutelius B, et al. Associations between socioeconomic status and major complications in type 1 diabetes: the Pittsburgh epidemiology of diabetes complication (EDC) study. Ann Epidemiol 2011;21:374-81.

9 Cutfield SW, Derraik JGB, Reed PW, et al. Early markers of glycaemic control in children with type 1 diabetes mellitus. PLoS One 2011;6:e25251.

10 Keenan HT, Foster CM, Bratton SL. Social factors associated with prolonged hospitalization among diabetic children. Pediatrics 2002;109:40-4.
11 Saydah S, Imperatore G, Cheng Y, et al. Disparities in diabetes deaths among children and adolescents - United States, 2000-2014. MMWR Morb Mortal Wkly Rep 2017;66:502-5.

12 Willi SM, Miller KM, DiMeglio LA, et al. Racial-ethnic disparities in management and outcomes among children with type 1 diabetes. Pediatrics 2015;135:424-34.

13 Sherr JL, Hermann JM, Campbell F, et al. Use of insulin pump therapy in children and adolescents with type 1 diabetes and its impact on metabolic control: comparison of results from three large, transatlantic paediatric registries. Diabetologia 2016;59:87-91.

14 Petitti DB, Klingensmith GJ, Bell RA, et al. Glycemic control in youth with diabetes: the search for diabetes in youth study. J Pediatr 2009; 155:668-72.

15 Hill Golden S. Coronavirus in African Americans and other people of color. Johns Hopkins medicine website, 2020. Available: https:// www.hopkinsmedicine.org/health/conditions-and-diseases/ coronavirus/covid19-racial-disparities

16 Stokes EK, Zambrano LD, Anderson KN, et al. Coronavirus disease 2019 case surveillance - United States, January 22-May 30, 2020. MMWR Morb Mortal Wkly Rep 2020;69:759-65.

17 Killerby ME, Link-Gelles R, Haight SC, et al. Characteristics associated with hospitalization among patients with COVID-19 - Metropolitan Atlanta, Georgia, March-April 2020. MMWR Morb Mortal Wkly Rep 2020;69:790-4.

18 Gold JAW, Wong KK, Szablewski CM, et al. Characteristics and clinical outcomes of adult patients hospitalized with COVID-19 - Georgia, March 2020. MMWR Morb Mortal Wkly Rep 2020;69:545-50.

19 Price-Haywood EG, Burton J, Fort D, et al. Hospitalization and mortality among black patients and white patients with COVID-19. N Engl J Med 2020;382:2534-43.

20 Millett GA, Jones AT, Benkeser D, et al. Assessing differential impacts of COVID-19 on black communities. Ann Epidemiol 2020;47:37-44.

21 Walker AF, Hood KK, Gurka MJ, et al. Barriers to technology use and endocrinology care for underserved communities with type 1 diabetes. Diabetes Care 2021:dc202753.

22 Levine BJ, Close KL, Dalton D, et al. Enhancing resources for healthcare professionals caring for people on intensive insulin therapy: summary from a national workshop. Diabetes Res Clin Pract 2020;164:108169.

23 Arora S. Project echo: democratising knowledge for the elimination of viral hepatitis. Lancet Gastroenterol Hepatol 2019;4:91-3.

24 Arora S, Kalishman SG, Thornton KA. Project ECHO: a telementoring network model for continuing professional development [published correction appears. J Contin Educ Health Prof 2017;37:239-44.

25 Cuttriss N, Bouchonville MF, Maahs DM, et al. Tele-rounds and case-based training: project echo Telementoring model applied to complex diabetes care. Pediatr Clin North Am 2020;67:759-72.

26 Walker AF, Hu H, Cuttriss N, et al. The neighborhood deprivation index and provider geocoding identify critical catchment areas for diabetes outreach. J Clin Endocrinol Metab 2020;105:3069-75.

27 HRSA-FQHC. Federally qualified health centers, 2018. Available: https://www.hrsa.gov/opa/eligibility-and-registration/health-centers/ fqhc/index.html\#: :text=Federally\%20Qualified\%20Health\% 20Centers\%20are,care\%20services\%20in\%20underserved\% 20areas

28 Lal RA, Cuttriss N, Haller MJ, et al. Primary care providers in California and Florida report low confidence in providing type 1 diabetes care. Clin Diabetes 2020;38:159-65.

29 Hemming K, Haines TP, Chilton PJ, et al. The stepped wedge cluster randomised trial: rationale, design, analysis, and reporting. BMJ 2015;350:h391. 